\title{
¿Dios castigador, Dios juez o Dios amado? Imágenes de Dios en medios católicos y pentecostales peruanos
}

\author{
God as punisher, judge or loving? \\ Images of God in Catholic and Pentecostal Peruvian media
}

\author{
Véronique Lecaros* \\ Universidad Jesuita Antonio Ruiz de Montoya ${ }^{1}$
}

\begin{abstract}
Resumen
Este articulo se propone analizar algunas aristas de la concepción de Dios de la piedad popular peruana. Tomando en cuenta las encuestas nacionales e internacionales, hemos organizado focus group principalmente con jóvenes formándose para los sacramentos o involucrados en grupos de oración. Intentamos mostrar cómo concepciones de Dios aparentemente contradictorias se articulan para conformar un Ser coherente que acompaña al fiel en su cotidiano. No se trata de una fe racional y razonada sino de una fe existencial del hic et nunc (Marzal, Romero, Ameigeras, Martín, Parker, de la Torre). En el imaginario culturalmente enraizado en las tradiciones, dominan percepciones divinas como de un juez temible, todo poderoso, ordenador del cosmos y eventualmente castigador del malvado; por otro lado, se expresa el cariño a un Dios protector y proveedor. Ambas perspectivas se armonizan y se complementan en un Dios garante del orden justo del mundo. En contexto evangélico, la concepción de Dios no varía mucho, se exacerba la importancia del poder divino. Esta estudio ayuda a entender la dificultad en la comprensión y aceptación del Dios de Misericordia: ¿cómo este Dios que no guarda cuentas puede garantizar el orden y la justicia?
\end{abstract}

Palabras claves: imágenes de Dios, Perú, piedad popular, misericordia divina, justicia divina.

\begin{abstract}
The aim of this article is to study some aspects of God's conception in the Peruvian popular piety. Taking into account international and national polls, we have mainly organized focus groups with young people preparing for sacraments or belonging to prayer groups. We try to demonstrate how apparently conflicting God's conceptions end up forming a coherent Being who accompanies the faithful in his daily life. In this context, faith is not a rational and reasoned one but an existential one involved in the hic et nunc (Marzal, Romero, Ameigeras, Martín, Parker, de la Torre). Among the images culturally rooted in traditions, predominate God's perceptions as a frightful and powerful judge ordering the cosmos and when necessary punishing evil people. On the other hand, people express their affection for a protecting and solution-supplier God. Both perspectives complement each other in a God warrant of a just world order. In evangelical context, God's conceptions are similar but the importance of divine power is enhanced. This investigation helps understand people's difficulty in grasping the meaning of the God of Mercy and accepting it: How can this God who does not keep track of evil actions be a warrant for order and justice?
\end{abstract}

Key words: God's images, Peru, popular piety, divine mercy, divine justice.

Artículo recibido el 15 diciembre de 2016 y aprobado el 13 de junio de 2017.

* Doctora en Teología (Estrasburgo). Docente y pesquisadora del Departamento de Humanidades - Sección Tabajo Social de la PUCP (Peru). Pesquisadora de la Univesidad Antonio Ruiz de Montoya, Peru. País de Origem: Peru. E-mail: vgauthier@pucp.pe

${ }^{1}$ Este artículo presenta algunos de los resultados de un proyecto de investigación sobre la secularización en América Latina financiado por la Conferencia Episcopal Italiana en la Universidad Antonio Ruiz de Montoya.

Horizonte, Belo Horizonte, v. 15, n. 46, p. 571-594, abr./jun. 2017 - ISSN 2175-5841 


\section{Introducción}

El antropólogo Manuel Marzal especialista de la religiosidad popular peruana $y$ en general latinoamericana resume en pocas palabras sus investigaciones (2004, p.20): "la clave de la religión del pueblo está en el significado que el pueblo latinoamericano da a ocho palabras ("devoción", "santo", "milagro", "castigo", "promesa", "bendición", "fiesta" y "peregrinación") recibidas en la evangelización colonial y reinterpretadas en su mundo cultural". Traduciendo estas nociones en término de relaciones con Dios y de imágenes divinas, el Dios de "la religión del pueblo" es un Dios todopoderoso, controlador quien premia con sus "bendiciones", los actos de "devociones", participaciones en "fiestas" y en "peregrinaciones" así como el cumplimiento de "promesas" y quien, con esta misma lógica, "castiga" a los que no acatan estas normas de rendimiento de culto (Marzal, 2002, p. 374). Como matices, se trata de una perspectiva compartida por muchos autores, tal como lo muestra Eloísa Martín (2007, p. 75) analizando varias obras dedicadas al tema. Sin embargo, la idea de Dios como de un Ser que lo controla todo, juzga, negocia (do ut des) y finalmente castiga no corresponde a la revelación cristiana según el magisterio.

En fidelidad con el aggiornamiento iniciado por Juan XXIII con el Concilio Vaticano II, muchos sacerdotes y religiosos críticos de concepciones divinas que según ellos, distorsionan la verdadera imagen de Dios revelada por su Hijo Jesús, se esfuerzan en "evangelizar y purificar la piedad popular", expresión del Documento Final de Aparecida (§262). En esta perspectiva, el Papa Francisco, quien como Cardenal Bergoglio, fue redactor del documento final de Aparecida, ha hecho de la promoción del Dios de Misericordia el eje central de su pontificado, escogiendo como devisa una expresión de Beda el Venerable, miserando atque eligendo (Misericordiae Vultus, §8) y promulgando al inicio de su pontificado un año de jubileo extraordinario de la Misericordia. 
Queda paradójico como nuestra investigación con responsables de pastoral y grupos de jóvenes lo ha arrojado, el diminuto éxito de los sacerdotes y religiosos en la predicación de la misericordia divina. ¿Porqué aferrarse tanto a un Dios que parece tan temible, perseguidor de sus devotos incumplidos? Esta sorprendente situación nos lleva a profundizar el sentido de estas concepciones de Dios. No se trata de simples creencias que al ser demostradas falsas, podrían entonces ser cambiadas por otras más acertadas y más acogedoras. ¿En qué se enraízan estas concepciones? ¿Tradiciones, contextos sociales, seguramente pero no hubiera algo más profundo? Es lo que nos proponemos demostrar. Abordaremos también el punto de vista evangélico: ¿el proceso de conversión que implica cambios de rituales significa realmente una transformación de imágenes divinas?

No pretendemos generalizar estas observaciones y reflexiones a todos los peruanos, de hecho hemos encontrado excepciones. Quisiéramos delinear una tendencia y mostrar cómo diferentes concepciones de Dios que pueden parecer contradictorias se articulan para conformar un Ser coherente que acompaña al fiel en su cotidiano.

\section{Metodología}

La noción de religiosidad popular como lo han subrayado varios especialistas de diferentes corrientes (DE LA TORRE, 2016; ALBERT-LLORCA, 2010; KEANE, 2008; AMEIGEIRAS, 2008) es tan polisémica que su significado se vuelve confuso. ¿Qué significa "popular" (DE LA TORRE, 2016, p. 479)? ¿De todos, de la mayoría, de los pobres, de los pocos educados, de los laicos que no han sido formados en teología? Marlène Albert-Llorca (2010, p. 1044) tomando en cuenta estas dificultades concluye que a la diferencia de América Latina donde todavía se sigue manejando esta expresión, hoy, en Europa, la noción de religiosidad popular no tiene cabida en un contexto de proliferación de creencias y de estilos de vida. 
El Directorio sobre la piedad popular y la liturgia, texto oficial de la Congregación para el Culto Divino y la Disciplina de los Sacramentos presenta así el tema (\$10): "La religiosidad popular no tiene relación necesariamente con la revelación cristiana. Pero en muchas regiones expresándose en una sociedad impregnada de diversas formas de elementos cristianos, da lugar a una especie de "catolicismo popular", en el cual coexisten más o menos armónicamente elementos provenientes del sentido religioso de la vida, de la cultura propia de un pueblo, de la revelación cristiana". En esta definición, la Congregación recoge una posición adoptada desde los años 6o, según De la Torre (2016, p. 479), por varios autores involucrados en misiones eclesiales, entre ellos Marzal. Consiste en deslindar al menos implícitamente por un lado la institución eclesial y la teología racional cuya misión es purificar la piedad popular y por otro lado, los laicos, los ritos tradicionales fuera de la liturgia oficial. Esta posición que implica definir la religiosidad popular por lo que no es, no ayuda mucho en entender su dinámica.

Aldo Ameigeiras tratando de salir de una perspectiva institucional, evaluadora y euro-céntrica, aborda el tema desde otro ángulo. Refiriéndose a Christian Parker (1993, p. 362) considera que existe en "la cultura popular latinoamericana otra lógica "alternativa a la racionalidad occidental dominante en la cultura del capitalismo transnacional" - "une lógica de la vida, de la emotividad, de la simultaneidad, del símbolo, de la sensibilidad frente a la lógica de la razón, de la forma, de la linealidad, de lo que es sucesivo y despersonalizado"; una lógica irrefutable de sobrevivencia" (2008, p. 307). En este contexto, la religiosidad popular no funciona según la lógica cartesiana de Emile Durkheim quien distingue dos conceptos opuestos, el sagrado y el profano (2008, p. 309). En el ambiente cultural latinoamericano, el sagrado no es experimentado como un fenómeno a parte sino que permea todo lo vivido (MARTíN, 2007). En palabras de Ameigeiras (2008, p. 312), "la religiosidad popular vehicula una cosmovisión dinámica muy capaz de articular diferentes situaciones de la vida cotidiana porque de cierta manera, ninguna escapa de la interpelación religiosa". Tomando en cuenta estas 
reflexiones, nos proponemos analizar algunos aspectos de las imágenes de Dios en contexto cultural peruano.

En nuestra investigación, aprovechamos los resultados de encuestas nacionales y internacionales tales como Pew Research, WV o Zogby. Consideramos que la pertinencia de encuestas sobre imágenes de Dios es limitada especialmente en América latina donde la religiosidad popular no es un discurso racional y reflexivo sino que corresponde a una manera de abordar situaciones concretas en un ambiente en el cual no existe separación alguna entre sagrado y profano (DE LA TORRE, MARTÍN, 2016; ALMEIGEIRAS, 2008; MARTÍN, 2007). En 2015, 2016, hemos llevado a cabo una investigación en Chiclayo, Jaén, San Ignacio y Lima². Hemos entrevistado a religiosos y líderes de centros de espiritualidad en particular el Centro de Espiritualidad Ignaciana en Lima y Emaús en Jaén, así como a profesores de religión y a los encargados de la piedad popular en la Conferencia Episcopal Peruana. Hemos organizado focus groups con jóvenes (edad 16 a 18 años) preparándose para la confirmación en Jaén (centro Emaús a cargo de las Hermanas Esclavas del Sagrado Corazón de Jesús) y San Ignacio (estudiantes de último año de colegio). En todos estos centros, los líderes promueven activamente la perspectiva sobre la misericordia divina del Papa Francisco. Además hemos organizado focus groups con jóvenes implicados en grupos de oración en Chiclayo y en Lima (zonas pudientes y zonas deprimidas). Finalmente, hemos confirmado nuestros resultados con múltiples entrevistas informales principalmente en Lima, en una diversidad de contextos ya sea ambiente de religiosidad popular (procesiones, conversaciones con miembros de hermandades) y ambiente cotidiano (taxistas, vendedores ambulantes...). En vez de preguntar por las creencias, hemos invitado los entrevistados a evaluar situaciones de injusticias o de incumplimientos de promesas. Para el análisis de los evangélicos (así se llaman en el Perú a todos aquellos cristianos que no son católicos), hemos aprovechado entrevistas y

\footnotetext{
2 Jaén (alrededor de 200000 habitantes con periferia) y San Ignacio (alrededor de 30000 con periferia) se ubican en el norte del Perú, en la frontera con Ecuador. La zona donde se ha desarrollado la investigación vive de la agricultura. Está poblado de migrantes provenientes de zonas rurales deprimidas, en este sentido es comparable a las zonas periféricas de Lima también poblada de personas de misma origen. Chiclayo es una ciudad norteña de medio millón de habitantes.
} 
observaciones participantes hechas en investigaciones anteriores (Lecaros, 2016a y b) y complementada con algunos focus groups. No pretendemos abarcar con estas observaciones y reflexiones todos los peruanos sino demostrar una tendencia.

\section{¿De qué Dios se habla?}

Como bien lo nota el biblista Manuel Diaz (2002, p. 9), las imágenes de Dios que manejamos son múltiples. Sin embargo, no son impresiones dispersas y sueltas, se articulan entre sí conformando lo que Luisa Broggi, directora del Centro de Espiritualidad Ignaciana, llama paradigma, retomando una expresión que atribuye a José María Vigil y John F. Wikham SJ. Ciertas características son consecuencias unas de las otras.

Sin excepción, todos los religiosos y en general encargados de formación espiritual entrevistados concuerdan con el análisis de Marzal y afirman que para la mayoría de los creyentes peruanos, Dios castiga. Sin embargo, en los focus groups y entrevistas se pudo llegar a un resultado mucho más matizado. A la pregunta directa: "¿piensas que Dios te puede castigar?", casi todos han respondido que no, inclusive en conversaciones informales con personas involucrados en ritos de piedad popular tal como lo menciona Marzal. Con más convicción y vehemencia, se han expresado los jóvenes en el centro Emaús de Jaén. Esta situación corresponde a los resultados arrojados por una encuesta de 2012 desarrollada entre jóvenes de centros parroquiales de 9 regiones del Perú (ANGÜIS; HUAMÁN; VEGA; EVERALDO, 2012, p. 81). La pregunta sobre la existencia de un castigo divino implica un rechazo mayoritario. Sin embargo, se mantiene en una proporción todavía significativa el temor al castigo de Dios, 32\% de jóvenes creen que Dios los puede castigar y $24 \%$ no se atreven a pronunciarse.

Pregunté a los jóvenes, especialmente a los de Jaén por su sensibilidad con el tema, si antes de empezar su formación pensaban que Dios castiga y como fue su experiencia de catequesis. Mencionaron que en su infancia, solían amenazarlos con 
el castigo divino para que se porten bien: "Dios te mira, ve todo lo que tú haces y te va a castigar si te portas mal". Este tipo de comentarios también se mencionaron en San Ignacio y en Lima.

Para analizar de que manera habían integrado la formación recibida, pregunté su opinión sobre situaciones de injusticias: "¿Qué pasa con la persona que ha agredido, robado, matado...?" La respuesta fue unánime, le va a ir mal en esta vida y definitivamente en la otra. Unos jóvenes de Jaén citaron un dicho que menciona también Marzal en su trabajo antropológico hecho en el Agustino a finales de los 80's (1988): "Dios tarda pero no olvida". Recurrieron también a otra expresión muy popular: "todo se paga en esta vida". Cuando pregunté directamente si Dios castiga a los malvados, noté un tiempo de reflexión pero la respuesta fue tajante: "sí, los castiga". Un joven en Jaén reflexionando sobre la delincuencia emitió la hipótesis aceptada por todo el grupo que los malvados "no creen en Dios". Un líder juvenil afirmó que al inicio de su preparación para la confirmación, la perspectiva de la hermana le dio pavor y trató de convencerla de cambiar de discurso: "Si les decimos que Dios no castiga, ise van a portar mal!".

De manera más sutil, una profesora de religión de San Ignacio que afirma luchar contra el prejuicio de un Dios castigador, estimula a los padres de familia para que tomen en serio los cursos de religión con estas palabras: "Si ubican a Dios en el último lugar, ¿Qué va a pasar si tienen un problema y Dios los ubica en el último lugar?".

En Chiclayo, en el grupo de jóvenes cuyas familias mantienen la devoción a la Cruz de Motupe, todos afirmaban no creer en el castigo divino, sin embargo, consideraban que los que no cumplían con su promesa de peregrinación a la Cruz tendrían serios problemas ("les van a ocurrir malas cosas"). Este mismo comentario que Marzal (1988, 2002) recogió en sus entrevistas, también lo he seguido escuchando entre devotos en Lima. Entre los peruanos migrantes residentes en New Jersey, convertidos a la devoción del Qoyllur Ritti, se sigue con 
el mismo comentario: "el Señor es bueno, te avisa, te cuida pero si no cumples con Él, te castiga" (ÁVILA, 2013, p.288). Los miembros de hermandades del Señor de los Milagros suelen comentar un poco en son de broma: "el anda pesa duro, icuántos pecados vamos a pagar!".

En cambio, entre los jóvenes de clase media limeña que participan regularmente en un grupo de oración dirigido por un religioso, tuve otros tipos de respuesta: Dios no castiga ni siquiera al malvado que puede tener problemas por su conducta más no directamente por acción divina. Desafortunadamente, en estos grupos, no pude precisar estas respuestas por la presencia de los religiosos muy atentos a la ortodoxia de su grey.

Por otro lado, para todos sin excepción, Dios interviene de manera milagrosa en el mundo. No se logró precisar la dinámica del milagro. Todos hablaban de los milagros como de algo misterioso pero no remoto, un joven en Jaén resumió bien el parecer general y fue aprobado con fuerza por los demás: "a Dios nada es imposible", expresión que regresó directamente o indirectamente en varios contextos.

\section{¿Dios castigador?}

Desde un primer abordaje resaltan aparentes incoherencias: se niegan la existencia de castigos divinos pero cuando se confronta a los entrevistados a situaciones concretas, se espera de Dios un castigo para poner orden y hacer justicia. En la encuesta hecha por Angüis et al. (2012), los jóvenes consideran mayoritariamente que si bien Dios no castiga (44\% más 24\% de indecisos), Él puede poner a prueba (76\% y 11\% de indecisos). La prueba es un término ambiguo que puede ser interpretado como una forma de castigo (un sufrimiento con mira a un bien), así me ha sido traducido por un entrevistado que afirmaba espontáneamente que Dios pone a prueba: "Dios te pone a prueba cuando has 
pecado para corregirte". Una encuesta internacional Zogby hecha en 2003 (JOHNSON, 2016, p. 62) confirma estos resultados. Se preguntó en varios países a personas de diferentes religiones si "podrían soportar consecuencias negativas al desobedecer [las normas de] su religión". 80\% de peruanos católicos respondieron que sí.

Esta primera lectura nos permite tomar en cuenta un matiz importante y muy revelador. Más que de un Dios castigador, los entrevistados en su inmensa mayoría se han referido a un Dios juez poderoso que retribuye a cada uno lo suyo. La diferencia entre un Dios castigador y un Dios que por poner orden eventualmente puede castigar descansa en el objetivo: la segunda alternativa pone el acento no en el castigo sino en la justa retribución. En esta cosmovisión, al hombre que desea ser bendecido, le toca obedecer a las normas divinas. La diferencia salta a la vista pensando en las representaciones del infierno por Jerónimo Bosh o en el tempano románico de Conques (Francia). Los suplicios del infierno en ambos casos son según la expresión del historiador Jean Delumeau (2015, p. 70) "sádicos y perversos". El teólogo Bernard Sesbouë se refiere al "Dios perverso" y al "Dios violento" como a "siniestras imágenes de Dios" que por siglos han permanecido en nuestro imaginario y que todavía a veces resurgen (1999, p.91) (Diaz, 2002, p.9). No cabe duda que todos los que entrevisté manejan una concepción más serena de un Dios que busca restablecer la justicia y puede poner a prueba pero sin imponer torturas al malvado. Aunque nuestra muestra no permita generalización, podemos suponer que estos cambios corresponden a una tendencia mundial favorecida por la Iglesia: el Dios "perverso" y "sádico" no encaja con la fe moderna. Debe quedar claro sin embargo que si Dios no es "sádico", es temible, "tarda pero no olvida".

\section{¿Dios juez todopoderoso?}

La imagen de Dios a quien "nada es imposible" implícitamente involucrada en los discursos de los entrevistados corresponde a lo que con cierta ironía, el Papa 
Francisco (2014) ha llamado un "mago con varita mágica, capaz de hacer todas las cosas". Esta imagen de un Dios juez todopoderoso está muy enraizada en el imaginario y en la vivencia de los peruanos porque en ella, se conjugan varios factores que la confortan y solidifican. Podemos distinguir tres corrientes interpretativas del fenómeno.

Interpretación pastoral histórica: La imagen del Dios Juez todo poderoso es conforme a la Biblia. André Wénin (CAUSSE; CUVILLIER; WÉNIN, 2011, p. 18) refiriéndose a una obra de Giuseppe Barbaglio comentando el Primer Testamento, considera que "en la Biblia coexisten principalmente dos imágenes de Dios. La primera es de un Dios con dos caras que recompensa y castiga [...]. Más excepcional, la segunda presenta un Dios de pura gracia (amor)". El Dios del Segundo Testamento, tampoco se queda atrás en su afán justiciero. Como lo nota Daniel Marguerat (BALMARY; MARGUERAT, 2016, p. 23) no existe libro de este Testamento, con la excepción de la carta a Filemón que no mencione el juicio final.

Según Thomas Römer (2009, p. 126), la concepción de un Dios que retribuye y pone orden en el Cosmos tiene su origen en el Medio Oriente de la Antigüedad. Es una convicción meditada por los sabios que buscan a partir de ella proponer los principios llevando a una vida harmoniosa y prospera. En pocas palabras un dicho del libro de Proverbios $(13,21)$ resume una perspectiva presente con matices en todos los libros de la Biblia: "el mal persigue a los pecadores y el bien recompensa a los justos". No obstante esta imagen de Dios en el Perú se refuerza por la lectura de la Biblia pero no proviene directamente de ella.

La concepción de este Dios juez imparcial se forjó en el Occidente cristiano y de esta manera llegó a América (ESTRADA, 2005, p. 99). Nollens Volens, san Agustín jugó un papel esencial en el desarrollo de esta cosmovisión. Interpretando la naturaleza humana en clave de pecado original y entonces de perversión, concibió a la humanidad como masa damnata. De la perdición, solo unos pocos por gracia divina pueden escapar (KASPER, 2012, p. 102; BASSET, 2014, p. 37). 
Aunque se esté desarrollando, por lo menos en algunos círculos católicos, una imagen más acogedora de Dios, se mantiene en América Latina profundamente ancladas en las mentalidades concepciones que no han cambiado mucho desde la primera evangelización (MARZAL, 2002; KLAIBER, 1988).

A estas circunstancias históricas, se añade el hecho que varios sectores de la Iglesia católica siguen en una perspectiva preconciliar respecto a este tema. El teólogo Walter Kasper quien ha inspirado la promulgación del año de la misericordia considera que en el siglo XXI, se debería imponer el "subrayado de la misericordia como tema central de la teología"(2012: p. 19), reparando así el "olvido" sistemático de la misericordia que Kasper considera como un problema esencial de los tratados sobre Dios (2012: p. 20). Refiriéndose a los "diccionarios enciclopédicos y manuales de teología" (2012: p. 19), Kasper califica de "decepcionante, incluso catastrófico" la casi ausencia de una mención a la misericordia divina.

Interpretación universalista: Dominic Johnson, desde una perspectiva pluridisciplinaria, en una obra de título provocativo (God is watching you, How the fear of God makes us human) intenta probar que el miedo al castigo nos lleva a superar nuestros intereses inmediatos para desarrollar comportamientos morales. Aprovechando los resultados de varias experiencias en psicología experimental desarrollada principalmente en EEUU, Johnson (2016, p. 113, 115) concluye que espontáneamente el ser humano, sin poder racionalizarlo, tiende a anticipar el castigo y la recompensa como resultado de su acción (p. 126): "tenemos un sentido profundamente enraizado que la gente debería obtener lo que merece".

La creencia pre-racional en un mundo esencialmente justo funciona para muchos como un reflejo, así lo muestra Johnson a partir de los experimentos que 
analiza3. Esta creencia prejuicio no implica una cosmovisión estructurada por un Dios todo poderoso que retribuye a cada cual lo suyo pero sin duda, la puede reforzar. En una encuesta del Pew research Center del 2008 (p. 215), se pregunta si la religión es necesaria para la moralidad. Johnson concluye que para la mayoría de los seres humanos, la religión juega un papel esencial en la moralidad. Sin embargo, existen diferencias abismales entre las regiones del globo que Johnson no toma en cuenta. En casi todos los países europeos, Israel, Australia y Canadá, una minoría de personas (menos de 20\% para Francia, España, UK) considera la religión como esencial en la formación ética. En países de África, Oriente Medio, Extremo Oriente y América latina, la proporción se invierte. La encuesta confirma nuestras observaciones: varios jóvenes emitieron la hipótesis que los delincuentes son ateos. El Pew Research Center considera que estas diferencias corresponden a niveles de desarrollo económico con la excepción de EEUU. Esta variante no es tan determinante si se observan bien los datos: hay demasiadas excepciones, Corea, Japón, Chile, Argentina... En cambio, la secularización (o la débil adhesión a las instituciones religiosas) constituye una variante significativa.

Alternativa político cultural: Entre los muchos pensadores que han abordado el paradigma de la secularización, cabe mencionar a Charles Taylor y Marcel Gauchet quienes ubicándose en la perspectiva de Emile Durkheim analizan la articulación entre concepción de Dios y orden social (ESTRADA, 2005, p. 98). Taylor describe en estos términos las sociedades tradicionales: "antes vivíamos en sociedades en las que la presencia de Dios era ineludible; la propia autoridad estaba vinculada a lo divino, y la vida pública resultaba inseparable de diversos tipos de invocaciones a Dios" (2004, p. 74). Para Gauchet (1985), en las sociedades tradicionales, la moral es heterónoma, es decir las personas obedecen a normas transcendentalmente fijadas por Dios e interpretadas en contexto cristiano por una

\footnotetext{
${ }^{3}$ La creencia en este tipo de Dios no implica necesariamente un comportamiento moral obedeciendo a las normas fijadas por Él. La teoría de Johnson se topa con una paradoja de la cual no logra dar cuenta. La mayoría de los países menos corruptos son a la vez los menos creyentes. No podemos en el marco de este artículo entrar en una crítica pormenorizada de la obra de Johnson pero el principal problema de su teoría proviene de los dos postulados no fundamentados y muy cuestionados a partir de los cuales se edifica: por una parte, el ser humano es naturalmente egoísta y debe ser domado para volverse altruista (BASSET, 2014: p. 83); por otra parte, las normas estrictas y la imposición de una obediencia ciega producen orden (PORTOCARRERO, 2004).
} 
jerarquía religiosa, la Iglesia. A medida que la sociedad se "desencanta", según el término acuñado por Max Weber, también empleado por Gauchet: "Dios se desantropomorfisa (neologismo de Gauchet que ilustra bien el cambio de un Dios que ya no se concibe según el modelo humano) en el terreno moral. Para de ser un Ser que prescribe y retribuye, guardando cuenta exacta de las conductas" (2004: p. 47).

La concepción de Dios de casi todos nuestros entrevistados corresponde a la que impera según Gauchet y Taylor en las sociedades tradicionales. De hecho, el Perú es considerado por los especialistas del tema una "tierra encantada" (título de la obra mayor de Marzal, 2002).

\section{¿Dios amoroso?}

Para muchos jóvenes de Jaén, la formación pastoral que critica paradigmas divinos representó una remoción. Luisa Broggi encargada del centro limeño de Espiritualidad Ignaciana comenta que varios religiosos se han derrumbado al oír cuestionar la imagen de un Dios juez todopoderoso. Parece paradójico el aferrarse a un Dios temible y hasta preferirlo al Dios de Misericordia. Consideramos que las diferentes interpretaciones presentadas dan cuenta del peso de las tradiciones culturales pero no explican el desconcierto y el pavor que suscita el Dios de Misericordia con sus brazos abiertos al pecador.

Los autores europeos o norteamericanos ya mencionados no toman en cuenta la importancia de la dimensión afectiva subrayada por Parker, Almeira y Martín. Marzal en uno de sus últimos artículos considera que: "el sentimiento religioso es la dimensión olvidada por los estudiosos de la religión en América Latina, hecho que resulta extraño al ser quizás el punto fuerte de la religión latinoamericana. Llamo sentimiento religioso al conjunto de reacciones afectivas que tiene a menudo el creyente durante la celebración del culto y de otros actos de su práctica religiosa" (2004: p. 25). 
Los obispos latinoamericanos tomaron muy en cuenta la dimensión afectiva en el Documento final de Aparecida. La piedad popular ( $\$ 258$ a 265) se interpreta en clave de cariño y ternura. En §259 resaltan estas expresiones: "cariños a los santos y a los ángeles", "gozo", "encuentro de amor", "ternura y cercanía de Dios", "amor", "expresión de un corazón". El cariño se evidencia particularmente en la relación a la imagen de Cristo, de la Virgen o de algún santo. La imagen cobra vida y se trata como a un ser muy querido. Los devotos suelen guardar consigo estampitas que tocan varias veces al día, es una manera de sentirse acompañado. En este sentido, el vocabulario de las procesiones es revelador, se refiere a la estatua como a una persona que "camina", "sale" (de su iglesia), "regresa", "pernocta" (en otra iglesia)... De esta manera, se entiende el uso reciente de la técnica audiovisual en la piedad popular. Alejandro Diez (2016) comenta cómo las personas que no han podido asistir a la fiesta o procesión pueden pasar horas mirando un video a menudo mal hecho y repetitivo. Solamente, con los seres más cercanos y queridos, uno se regocija así de simplemente mirarlos.

Desde un punto de vista de psicología social, los devotos experimentan un amor profundo capaz de compensar y mitigar las carencias. Honneth inspirándose en las teorías de Winnicott afirma que "porque una única experiencia de amor no es suficiente para mantener la confianza en sí durante toda una vida, las personas son en general dependientes de repeticiones de experiencias de reconocimiento de tipo simbiótico" (2012, p. 206). Los adultos suelen buscar regularmente estas experiencias que los regresan a la etapa inicial de fusión con la madre (o el cuidador). En términos de Winnicott, estos momentos juegan el papel de "objetos de transición" para ayudar a soportar el stress que conlleva la "aceptación de la realidad". Para Winnicott, el arte o la religión pueden jugar el papel de objetos transicionales. Las imágenes y las estatuas vueltas seres animados funcionan como "objetos transicionales". Además, en el contexto de una fiesta popular, la vivencia simbiótica también se experimenta con los demás participantes una perspectiva no directamente estudiada por Winnicott pero fundamental para la teoría del 
reconocimiento de Honneth (LECAROS, 2016b) llamado por este autor "vida intersubjetiva del grupo".

Tomando en cuenta la dimensión afectiva, se evidencia que no existe contradicción entre el Dios del cariño y el Dios juez, son en realidad dos caras complementarias de una misma realidad. En una zona como Jaén en particular donde la corrupción solapada o abierta es constante, donde las instituciones estatales y los servicios públicos son muy deficientes, el verdadero amor de un Dios solamente cobra sentido si se manifiesta interviniendo en favor del devoto en los múltiples retos del cotidiano. En palabras de Catalina Romero, se suele interpretar como "milagro" cualquier situación positiva, "el milagro de la supervivencia diaria, de salir vivos de un hospital, del final de un juicio cuando no se esperaba nada de los jueces, de encontrar la solidaridad del prójimo" (ROMERO, 2013, p. 605).

Si Dios no es juez, no restablece y no garantiza un orden justo, entonces el hombre se encuentra solo en un vacío existencial. Como lo expresó magistralmente Epicuro en un texto citado por Lactancio (De ira Dei, capi. 13), "O Dios quiere suprimir los males y no lo puede; o lo puede y no lo quiere; o lo quiere y lo puede. Si lo quiere y no lo puede, es impotente. Si lo puede y no lo quiere, es malvado. Si lo quiere y lo puede, ¿de dónde tantos males y porque no los suprime?". Las reacciones fuertes que pueden llegar al derrumbe entre algunos religiosos tienen sentido en esta perspectiva: si Dios no juzga, no pone orden, entonces no es un Dios de Amor y el ser humano se encuentra abandonado y confrontado sin recurso a un mundo malvado o sin sentido.

\section{¿Cambiar de religión, cambiar de Dios?}

América Latina, una región casi exclusivamente católica hasta hace unas décadas, ha experimentado un cambio profundo en término de pertenencia religiosa. Según la última encuesta del Pew Research Center de 2014, solamente 69\% de la población es ahora católica, 19\% es protestante ("evangélico" como se le 
suele denominar en América Latina), 8\% no afiliada, 4\% práctica otra religión. Según esta misma encuesta, $76 \%$ de los peruanos se afirman católicos, 17\% evangélicos, 4\% no afiliados, 3\% de otra religión. En su gran mayoría, 65\% de los evangélicos, según el Pew Research Center, son de tipo (neo)pentecostal. Los evangélicos peruanos conforman una nebulosa muy dinámica. Hubieron grandes cambios desde los primeros grupos pentecostales huyendo del "mundo" y de sus tentaciones hasta las Iglesias de hoy que se implican en política con miras a subsanarla y a transformarla (AUBRÉE, 2010). Actualmente, por la influencia que ejercen los grupos exitosos, entre ellos los de corte neo-pentecostal afines a la teología de la prosperidad, se evidencia una tendencia a una cierta uniformización; por ejemplo, las Asambleas de Dios, Iglesia pentecostal tradicional, como muchas otras Iglesias, ha adoptada la organización en células inspirada en una formula del coreano Paul Yongi Cho (LECAROS, 2016a,b).

Sin poder desarrollar a fondo el tema quisiéramos abordar algunos aspectos de los debates en curso sobre el significado de estos nuevos fenómenos: ¿Cambiar de religión significa cambiar de Dios o quedarse con el mismo Dios pero adorarlo de manera diferente? Argüimos que con matices la segunda alternativa es la verdadera. Algunos autores negando diferencias fundamentales consideran el (neo)pentecostalismo como un "neo-catolicismo" o "catolicismo de substitución" (AUBRÉE, 2010, p. 877)4.

El Dios de los (neo)pentecostales presenta con matices características similares al Dios de la piedad popular católica. Se trata un Ser todo poderoso que se involucra milagrosamente en la vida del creyente, premiándolo o castigándolo ("bendiciendo" o "maldiciendo", según la fórmula consagrada inspirada de la

\footnotetext{
${ }^{4}$ Nos parece importante mencionar un debate que lanzó Olivier Roy y que merecería mayor reflexión. Roy en un libro de título provocador, La sainte ignorance, le temps de la religion sans culture (2008, p. 239), considera que los evangélicos exigen de sus adeptos una superación, eliminación de la cultura dominante (no fiestas, no baile, no alcohol, no imagen, no procesión...) de tal manera que se vuelven un caso ejemplar de religión sin cultura, es decir religión sin tradición. Jean Pierre Bastian (2009) contesta que no existe una desconexión en América latina porque "la cultura es todavía fundamentalmente religiosa y católica"; se trata de una "reformulación del vinculo entre cultura y religión". Estas dos perspectivas corresponden a dos caras de la misma moneda. La concepción de Dios puede ser considerada como la bisagra, la piedra angular de la cosmovisión que se mantiene y que facilita el tránsito de una religión a la otra mientras que por otro lado, los evangélicos luchan contra todos los otros rasgos culturales. Se tratan de tradiciones que en particular con la llegada a las ciudades pierden de su arraigo (LECAROS, 2015).
} 
Biblia). El vocabulario que domina los himnos es revelador: "Señor de los Ejércitos" es la designación favorita de Dios. En los cantos de alabanza se recogen expresiones bíblicas que manifiestan el absoluto poder de un Dios guerrero en lucha contra el diablo al cual se le atribuye todos los problemas y obstáculos que encuentran los fieles (DORÉ, 2013: p. 68). Para estimular la generosidad en el momento de recoger el diezmo, los pastores suelen referirse al pasaje de Malaquías (3, 8-11) que resalta la imagen de un Dios poderoso justo retribuyente (Lecaros, 2016, p.128). Como lo subrayan los especialistas del tema, este Dios se involucra directamente en el cotidiano operando milagros, resolviendo todo tipo de problemas, de salud, de pobreza y de familia para los fieles que se mantienen firmes en su fe (JENNINGS, 2015; CHESNUT, 2003; CORTEN, 1995; BASTIAN, 1997). Uno de los lemas favoritos en medio evangélico es: "Jesús es la solución". Como lo nota Allan Anderson (2005; ver también Aubrée, 2010), la teología pentecostal en América latina o en África tiene una dimensión existencial, toma en cuenta y asume todos los aspectos de la vida humana sin distinción entre sagrado y profano. Varios evangélicos resumían sus convicciones a la Pastora socióloga Uta Ihrke: "simplemente Jesús". Esta "teología fácil", según el término de Marzal inspirado por Troeltsch (Marzal, 1988, p. 419), centrada en un Dios todo poderoso, garante de un justo orden cósmico, presenta los mismos resortes que el catolicismo popular, de allí la facilidad con la cual se mueven los fieles del catolicismo al evangelismo, buscando a veces un Dios más eficiente (CHESNUT, 2003).

La encuesta reciente sobre América Latina del Pew Research Center confirma estudios anteriores y revela que en medio evangélico se tienden a exacerbar las características divinas de juez severo e implacable. Según sus datos, más evangélicos que católicos creen en el infierno: en Perú, 66\% de la población cree en la existencia del infierno y existe una diferencia de $13 \%$ entre evangélicos y católicos. Una mayor proporción de evangélicos se adhieren a las normas morales (prohibición de la homosexualidad, del aborto, de las relaciones sexuales antes del matrimonio y del consumo de alcohol). Además, la mayoría de los latinos, con mayor proporción de los evangélicos, creen en un Dios premiador. A la pregunta si 
Dios da fortuna y buena salud a los que tienen suficiente fe, en Perú, $73 \%$ de católicos responden que sí y $81 \%$ de evangélicos lo hacen.

En la piedad popular católica, el Dios juez es también y principalmente un Dios amoroso, cercano, atento a las necesidades del fiel. En medio evangélico, desaparece el soporte material y visual de las estatuas y de las imágenes que es reemplazado por la Biblia en general leída en la versión anticuada de la Reina Valera lo cual ensancha aun más la distancia con la Palabra divina. No obstante, la dimensión afectiva perdura pero con algunas transformaciones. Es cierto que se mantiene este Dios milagroso sigue manifestándose en el cotidiano del fiel. Sin embargo, el amor no se deja reducir a una perspectiva instrumental y utilitarista.

Para Durkheim, la religión se origina en experiencias colectivas de transportes de entusiasmo que llama "efervescencia" (Durkheim, 1912). En esta perspectiva, Jennings interpreta el pentecostalismo y justifica su éxito (2015, p. 70): "En el pentecostalismo, los participantes se encuentran con un fenómeno religioso que les ofrece por una parte experiencias extáticas, en general mezcladas con una creencia primitiva y aparentemente mágica en la posibilidad de curación y milagros y por otra parte la certeza de conectar directamente los participantes con la fuente divina". Las reflexiones previamente mencionadas de Honneth inspiradas en Winnicott permite mostrar que desde el punto de vista emocional, no existe diferencia radical entre el Dios de la piedad popular católica y el Dios pentecostal. En la perspectiva de Honneth quien menciona a Durkheim sin desarrollar mucho el tema, la efervescencia pentecostal puede entenderse como una forma de experiencia simbiótica que implica una estrecha relación con Dios y una intensa "vida inter-subjetiva de grupo". En el pentecostalismo, la cercanía con lo divino se acrecienta en cierto modo. La asistencia a los cultos es frecuente. El fiel busca la presencia divina de múltiples maneras a tal punto que invade su cotidiano: lectura de la Biblia, afiches pegados en su casa y en su lugar de trabajo con versículos de la Biblia, constantes referencias a la Biblia en las conversaciones... Además, el evangélico suele acompañar sus quehaceres con los cantos usados en los cultos de esta manera se mantiene a pequeña dosis la experiencia extática. 


\section{Conclusión}

Recorriendo algunas aristas de la concepción de Dios en medio católico y pentecostal peruano, se evidencia que no se trata de una representación intelectual sino de una realidad existencial que da pautas y sentido para el buen vivir. Los principales rasgos de estas imágenes corresponden a un temible Dios juez justo todopoderoso y sin embargo, cercano y atento a su criatura. Esta concepción se enraíza profundamente en las tradiciones, la cultura comunitaria y la psicología, además se refuerza a menudo por un estilo de pastoral y de lectura bíblica. Esta concepción es tan profundamente anclada en las mentalidades que la conversión del catolicismo al pentecostalismo no implica cambios significativos en las imágenes de Dios.

Sin embargo este Dios que "nunca olvida" y hace "pagar" las deudas en este mundo y en él otro, poco tiene que ver con el Dios de misericordia que pregona el Papa Francisco como lo han hecho sus predecesores desde Juan XXIII. Pensar la misericordia lleva a un dilema que así resume Kasper: "¿cómo puede ser compatible la justicia de Dios con el hecho de que él sea misericordioso y no castigue a los pecadores?" (2012, p. 21) (PÉREZ, 2016: p. 42). Por este motivo, en Misericordiae Vultus, el Papa Francisco insiste sobre la articulación entre justicia y misericordia: "la misericordia no es contraria a la justicia", sin embargo esta última sola es muy limitada y "Dios la supera con la misericordia y el perdón" (§21). La misericordia implica un recorrido que lleva al perdón de los pecados y del perdón a la conversión del pecador, así se supera el orden de la justicia retributiva. De manera significativa, el Papa Francisco insiste sobre la dimensión amorosa que conlleva la misericordia y permite así desarrollar otra lógica para remplazar la implacable contabilidad de la justicia retributiva. Para el Papa, la misericordia representa una "experiencia de la ternura del perdón" que es también "experiencia del amor, fundamento de una verdadera justicia" (§21). Cabe recalcar que a parte de los encargados de centros espirituales y de los religiosos, muy pocos, en nuestras entrevistas, han mencionado el perdón y han contemplado la posibilidad que el 
malvado sea amado por Dios, pueda arrepentirse, ser perdonado y no "pagar" en esta vida o en la próxima.

Rehabilitando a la misericordia como clave central y esencial para entender el proyecto salvífico divino, los teólogos modernos, la Iglesia católica y algunas Iglesias protestantes contribuyen a mantener el cristianismo en su papel profético de interlocutor, cuestionador y orientador existencial. Para Luisa Broggi, directora del Centro limeño de Espiritualidad Ignaciana, cambiar de paradigma del Dios juez al Dios de misericordia implica un largo proceso de reestructuración psicológica y espiritual para entrar en una dinámica de perdón. La misericordia como lo afirma el Papa Francisco (§14) es "una meta que se busca alcanzar y que implica compromiso y sacrificio".

La misericordia lejos de clarificar confusiones implica nuevos retos conceptuales. Muchos teólogos europeos modernos, entre ellos Barth, Von Balthasar, Kasper, Martelet, han centrado gran parte de su reflexión sobre la paradoja y el eventual sentido de un infierno eterno coexistiendo con un Dios poderoso y misericordioso: ¿cómo Dios puede en su misericordia dejar a un alma en un sufrimiento eterno? Por otro lado, si no existe el infierno, entonces la libertad humana se vuelve un concepto vacio. Sin posibilidad de negar a Dios, no hay verdadera libertad. No obstante, si no tenemos capacidad para salvarnos solos ¿cómo podríamos tener capacidad de perdernos solos? (KASPER, 2012, p. 103; MARTELET, 2007: p. 468).

Estos retos teológicamente legítimos se quedan muy lejos de las vivencias y de las angustias de los fieles latinoamericanos. Si la justicia distributiva podría eventualmente ser superada por la misericordia, ¿qué pasa con la vertiente pragmática de la justicia distributiva? ¿qué hay del Dios que interviene en nuestro mundo, protege, cura, pone orden, hace milagros pero sobre todo hace que todo se haga como por milagro, el policía que agarra al ladrón y recupera mi bolsa, el cirujano ético y buen profesional que maneja el bisturí y me recupera de un cáncer? 
Esta pregunta que no es de teólogos es la relevante para quienes han puesto su confianza en el Dios justo de las causas imposibles hic et nunc.

\section{BIBLIOGRAFÍA}

ALBERT-LLORCA, M. Religion populaire. In: AZRIA, R.; HERVIEU-LEGER, D. Dictionnaire des faits religieux. Paris: PUF, 2010, p1041-1044.

ALTAMIRANO, T.; ÁVILA, J. "Qoyllor Ritti transnacional: un culto andino”. In: SÁNCHEZ, J.; CURATOLA, M. (ORG.). Los rostros de la tierra encantada, Lima: PUCP, 2013, p.269-297

AMEIGERAS, A. "Culture populaire et religion": approches théoriques de la religiosité populaire au sein des cultures populaires latino-américaines. Social Compass, Londres, v. 55, n. 3, 2008, pp 304-316.

ANDERSON, A. Pentecostal and charismatic theology. In: FORD, D. The modern theologians: Blackwell Publishing, 2005, p. 589-607.

ANGÜIS, R.; HUAMAN, A.; VEGA, C. E.; EVERALDO, Z. Joven, Qué dices de Dios?, Aportes de un sondeo. Lima: CEP, Instituto Bartolomé de las Casas, 2012.

AUBREE, M. Pentecôtisme / néo-pentecôtisme. In: AZRIA, R.; HERVIEU-LEGER, D. Dictionnaire des faits religieux . Paris: PUF, 2010, p.875-882.

BALMARY, M.; MARGUERAT, D. Nous irons tous au paradis. Paris: Albin Michel, 2016.

BASSET, L. Oser la bienveillance. Paris: Albin Michel, 2014.

BASTIAN, J. P. Commentaire revue du livre d'O. Roy, La Sainte ignorance. Revue d'Histoire et de Philosophie Religieuse: Strasbourg, v. 89, n. 2, 2009.

BASTIAN, J. P. La mutación religiosa de América Latina. México DF: CFE, 1997.

Catecismo de la Iglesia Católica. 1992.

CAUSSE J. D.; CUVILIER E.; WENIN A. Divine violence, Approche exégétique et anthropologique. Paris: Cerf, Mediaspaul, 2011.

CHESNUT, A. Competitive spirit. New York: Oxford University Press, 2003. 
CONGREGACIÓN PARA EL CULTO DIVINO Y LA DISCIPLINA DE LOS

SACRAMENTOS. Directorio sobre la piedad popular y la Liturgia, 2001.

CONILL, J.; ESTRADA, J. A.; FRAIJÓ, M.; GÓMEZ, J.; MARDONES, J. M.; TORRES, A. Hay lugar para Dios hoy? Madrid: PPC, 2005.

CORTEN A. Le pentecôtisme au Brésil: émotion du pauvre et romantisme théologique. Paris: Karthala, 1995.

DELUMEAU, J. L'avenir de Dieu. Paris: CNRS éditions, 2015.

DIAZ, M. Imágenes de Dios y dignidad humana. Lima: CEP, 2002.

DIEZ, A. "Antiguos y nuevos temas sobre la fiestas patronales en los Andes del Perú". In:

ROMERO, C. Perú, país católico y diverso. Lima: PUCP, 2016, p.61-87

Documento Final de Aparecida. V Conferencia General del Episcopado

Latinoamericano y de El Caribe, 2007.

DORE, E. Lima Labyrinthe urbain, quête de modernité et désarroi identitaire dans un quartier populaire. Paris: L'Harmattan, 2013.

DURKHEIM, E. Las formas eleméntales de la vida religiosa. México: Fondo de Cultura Económica, 2013. (1912, primera edición).

FERRY L.; GAUCHET, M. Le religieux après la religion: Paris, Grasset, 2004.

GAUCHET, M. Le désenchantement du monde. Paris: Gallimard, 1985.

HONNETH, A. The I in We. Cambridge: Polity Press, 2012. Translated from German, Das Ich im Wir.

IHRKE, U. Religious mobility and social aspirations of Neopentecostals in Lima, Peru. Munster: LIT Verlag, 2014.

JENNINGS, M. An extraordinary degree of exaltation: Durkheim, effervescence and Pentecostalism's defeat of secularization. Social Compass, London, v. 62, n. 1, 2015, p.61-75.

JOHNSON, D. God is watching you, how the fear of God makes us human. Oxford: University Press, 2016.

KASPER, W. La misericordia, clave del evangelio y de la vida cristiana. Santander: Sal Terrae, 2012.

KEANE, W. The evidence of the senses and the materiality of religion. The Journal of the Royal Anthropological Institute, London, v. 14, 2008, pp 110-127.

KLAIBER, J. La Iglesia en el Perú. Lima: PUCP, 1988. 
LECAROS, V. La Iglesia Católica y el desafío de los grupos Evangélicos, el caso del Perú en América Latina. Lima: Universidad Antonio Ruiz de Montoya, 2016b.

LECAROS, V. La conversión al evangelismo. Lima: PUCP, 2016a.

LECAROS, V. Los católicos y la Iglesia en el Perú; un enfoque desde la antropología de la religión. Cultura y Religión, Iquique, v. 9, n. 1, nov. 2015, p. 34-50.

MARTELET, G.; ENFER. In: JEAN-YVES LACOSTE. Dictionnaire critique de théologie. Paris: PUF, 2007, p. 468-471.

MARTÍN, E. Aportes al concepto de religiosidad popular. In: CAROZZI, M. J.; CERIANI, C. Ciencias sociales y religión en América Latina; perspectivas en debate. Buenos Aires: Biblos, 2007, p. 61-87.

MARZAL M. Los caminos religiosos de los inmigrantes en la gran Lima. Lima: PUCP, 1988.

MARZAL M. Tierra encantada. Lima: PUCP, 2002.

MARZAL, M. Algunas preguntas pendientes sobre la religión en América Latina. In: Marzal, M.; Romero, C.; Sánchez, J.; (Org.). Para entender la religión en el Perú 2003. Lima: PUCP, 2004, p. 15-48.

PAPA FRANCISCO. Discurso del Santo Padre Francisco con motivo de la inauguración de un busto en honor del Papa Benedicto XVI. Sesión plenaria de la Academia Pontificia de las Ciencias, 2014.

PAPA FRANCISCO. Misericordiae Vultus. Bulla de convocación del Jubileo Extraordinario de la Misericordia, 2015.

Parker, C., Otra lógica en América Latina, Religión popular y modernización capitalista, Santiago de Chile, Fondo de Cultura Económica, 1993.

PÉREZ, G.; CRESPO, L. F. Elogio de la misericordia. Lima: IBC, CEP, 2016.

PORTOCARRERO, G. Rostros criollos del mal: cultura y transgresión en la sociedad peruana. Lima: Red para el desarrollo de las Ciencias Sociales en el Perú, 2004.

Römer; T. Dieu obscur, cruauté, sexe et violence dans l'Ancien Testament. Genève: Labor et Fides, 2009.

ROMERO, C. Por el encanto de una tierra. In: SÁNCHEZ, J.; CURATOLA M. (Org.). Los rostros de la tierra encantada. Lima: PUCP, 2013, p. 607-615

ROY, O. La sainte ignorance, le temps de la religion sans culture. Paris: Seuil, 2008.

SESBOÜE, B. Croire. Paris: Mame, 1999. 
TAYLOR, C. Las variedades de la religión hoy. Barcelona, Buenos Aires, México: Paidós, 2004.

TORRE DE LA, R.; MARTIN, E. Religious studies in Latin America. Annual Review of Sociology, Palo Alto, 2016, v. 42, pp. 473-492.

WEBB, K., The evidence of the senses and the materiality of religion. The Journal of the Royal Anthropological Institute, London, v. 14, 2008, pp 110-127.

WENIN, A. La Bible ou la violence surmontée. Paris: Desclée de Brouwer, 2008. 